\title{
Effects of Lactobacillus casei Shirota on immune function
}

\author{
H. Dong ${ }^{1}$, I. Rowland ${ }^{1}$, K. M. Tuohy ${ }^{1}$, L. V. Thomas ${ }^{2}$ and P. Yaqoob ${ }^{1}$ \\ ${ }^{1}$ The University of Reading, Whiteknights, P.O. Box 226, Reading RG6 6AP, UK and ${ }^{2}$ Yakult UK Ltd, Artemis, \\ Odyssey Business Park, West End Road, Ruislip HA4 6QE, UK
}

\begin{abstract}
Modulation of host immunity is an important potential mechanism by which probiotics confer health benefits. This study was designed to investigate the effects of a probiotic strain Lactobacillus casei Shirota (LcS) on immune function using human peripheral blood mononuclear cells (PBMC) in vitro. In addition, the role of monocytes in LcS-induced immunity was also explored.
\end{abstract}

Methods: PBMC were obtained from 5-19 healthy adults. LcS were grown anaerobically in MRS broth and harvested in the exponential phase. PBMC $\left(1 \times 10^{6}\right.$ cells $\left./ \mathrm{ml}\right)$ were exposed to three different concentrations of viable LcS for $24 \mathrm{~h}$ with or without $2.5 \mu \mathrm{g} / \mathrm{ml} \mathrm{ConA}$. The activation markers, CD69 and CD25, on T cell subsets were assessed by flow cytometry. For measurement of cytokine production, PBMC were stimulated for $24 \mathrm{~h}$ by three different concentrations of viable LcS with or without $1 \mu \mathrm{g} / \mathrm{ml} \mathrm{LPS}$ and cytokines were measured by ELISA. Natural killer (NK) cell activity stimulated by LcS at $10^{6} \mathrm{CFU} / \mathrm{ml}$ was assessed by flow cytometry, using K562 cells as target cells. Monocytes were depleted from PBMC by magnetic beads. PBMC and monocyte-depleted PBMC were compared for their response to LcS-induced activation and cytokine production.

Results: In the absence of ConA, LcS-induced expression of both CD69 and CD25, in particular, on CD8 ${ }^{+}$T-cells $(P<0.001)$. The maximal effect was seen with $10^{6} \mathrm{CFU} / \mathrm{ml}$, representing an LcS: PBMC ratio of $1: 1$. LcS alone induced production of IL-1 $\beta$, IL-6, TNF- $\alpha$, IL-12 and IL-10 $(P<0.001)$. In the presence of LPS, LcS promoted IL-1 $\beta$ production, but inhibited LPS-induced IL-10 and IL-6 production, and had no further effect on TNF- $\alpha$ and IL-12 production. NK cell activity was greatly promoted by LcS. Monocyte-depletion significantly reduced the impact of LcS on lymphocyte activation and cytokine production.

Conclusions: LcS preferentially activates cytotoxic lymphocytes in both the innate and specific immune system, which suggests that LcS could potentiate the destruction of infected cells in the body. LcS also induces both pro-inflammatory and anti-inflammatory cytokine production in the absence of LPS, but inhibits LPS-induced cytokine production. Monocytes play an important role in LcS-induced immunological responses.

This research was sponsored by Dorothy Hodgkin Postgraduate Awards and Yakult UK. 